\title{
Influência de Fatores Antinutricionais da Leucena (Leucaena leucocephala e Leucaena cunningan) e do Feijão Guandu (Cajanus cajan) Sobre o Epitélio Intestinal e o Desempenho de Frangos de Corte ${ }^{1}$
}

\author{
Paulo Batista de Oliveira ${ }^{2}$, Alice Eiko Murakami ${ }^{3}$, Elis Regina de Moraes Garcia ${ }^{4}$, \\ Marcos Macari ${ }^{5}$, Cláudio Scapinello 3
}

\begin{abstract}
RESUMO - Um experimento foi conduzido para avaliar a influência de fatores antinutricionais de alguns alimentos sobre o epitélio intestinal e o desempenho de frangos de corte. Foram utilizados 480 pintos de um dia de idade, em um delineamento inteiramente casualizado com quatro tratamentos ( $\mathrm{A}$ = ração testemunha à base de milho e soja; $\mathrm{B}=$ ração contendo Leucaena leucocephala $-6 \%$ [LL]; $\mathrm{C}=$ ração contendo Leucaena cunningan - $6 \%$ [LC] e D = ração contendo feijão guandu - Cajanus cajan - 20\% [CC]), quatro repetições e 30 aves por unidade experimental. Houve redução de ganho de peso e aumento da conversão alimentar com a utilização de LL e LC, no período de 1 a 21 e de 1 a 42 dias de idade. Aos 21 dias de idade, observou-se aumento no tamanho dos vilos do jejuno e na relação vilo:cripta do jejuno e íleo, nas aves que receberam $L C$. Houve aumento significativo $(\mathrm{P}<0,05)$ das células caliciformes no duodeno e jejuno em aves de todos os tratamentos e apenas LL e LC aumentaram as células caliciformes do íleo. Aos 42 dias de idade, houve aumento no número de células caliciformes causado por CC no duodeno e por LL, LC e CC no íleo. O consumo de ração e a profundidade de cripta não foram influenciados. A alteração da morfologia da vilosidade do jejuno, bem como a alteração na relação vilo:cripta no período inicial, influenciou negativamente o ganho de peso e a conversão alimentar nos períodos inicial e total.
\end{abstract}

Palavras-chave: Cajanus cajan, epitélio intestinal, fatores antinutricionais, frangos de corte, Leucaena cunningan e leucocephala

\section{Influence of Antinutritional Factors of Leucaena (Leucaena leucocephala and Leucaena cunningan) and Pigeous Bean (Cajanus cajan) on the Intestinal Epithelium and Performance of Broiler Chickens}

\begin{abstract}
A trial was conducted to evaluate the influence of antinutritional factors in some feedstuffs on broiler chick's performance and intestinal epithelium. A total of 480 one-day old broiler chicks were allotted to a completely randomized experimental design with four treatments $(\mathrm{A}=$ corn and soybean meal based control diet; $\mathrm{B}=$ diet containing Leucaena leucocephala $-6 \%$ [LL]; $\mathrm{C}=$ diet containing Leucaena cunningan $-6 \%[\mathrm{LC}]$ and $\mathrm{D}=$ diet containing Pigeous bean - Cajanus cajan - $20 \%[\mathrm{CC}]$ ), four replicates and 30 broiler chicks per experimental unit. The broiler chicks, which were fed with LL and LC containing diets showed lower weight gain and a worse feed: gain in the periods from 1 to 21 and from 1 to 42 days of age. At $21^{\text {st }}$ days of age only the broiler chicks fed with LC containing diet showed a higher villi size in jejunum and villi: crypt ratio in jejunum and ileum. There was significant increase on the number of Goblet cells in the duodenum and jejunum in the broiler chicks of all treatments at the $21^{\text {st }}$ day of age, and only broiler chicks fed with LL and LC containing diets showed an increased number of Goblet cells in the ileum. At $42^{\text {th }}$ day of age, an increase of Goblet cells was observed in the duodenum of broiler chicks fed with CC containing diets, and in the ileum of broiler chicks fed with LL, LC e CC containing diets. Feed intake and crypt depth were not influenced by treatments in any of the experimental periods. Alterations on jejunum villi morphology, villi: crypt ratio and increased number of Goblet cells in the initial period resulted on a worse weight gain and feed: gain in the initial and total growth periods of the broiler chicks.
\end{abstract}

Key Words: Cajanus cajan, intestinal epithelium, antinutritional factors, broilers chicks, Leucaena cunningan and leucocephala

\section{Introdução}

Oscilações sazonais nos preços dos alimentos que compõem as dietas dos animais de produção levam os nutricionistas a buscarem constantemente alimentos alternativos que possam substituir de forma adequada e econômica os produtos tradicionalmente utilizados na elaboração de rações. No entanto, uma das maiores limitações na utilização destes produtos de origem vegetal é a presença de fatores antinutricionais que podem diminuir a digestibilidade dos nutrientes da dieta, afetando o desempenho animal.

\footnotetext{
1 Parte da Dissertação de Mestrado do primeiro autor (UEM).

2 Professor da UEMS - Rodovia Aquidauana-Cera, Km 12 - 79200-000 - Aquidauana, MS. E.mail: zootuems@zoonet.com.br

3 Professor Depto. Zootecnia - UEM - Av. Colombo, 5790 - Maringá - PR - 87020-900.

4 Professor do Curso de Zootecnia - UEMS - Aquidauana - MS. E.mail: ermgarcia@hotmail.com.br

5 Professor Depto. Morfologia e Fisiologia Animal - UNESP - Jaboticabal - SP.
} 
Além disso, o processamento para inativação dessas substâncias nem sempre apresenta resultado satisfatório e muitas vezes o custo destes procedimentos pode tornar o emprego desses alimentos economicamente inviável.

DIBNER et al. (1996), verificando o efeito da idade e dos ingredientes da dieta sobre o epitélio intestinal de aves, concluíram que o funcionamento do trato gastrointestinal está intimamente relacionado com as estruturas do epitélio intestinal. Constataram também que as aves adultas também sofrem influência dos ingredientes da dieta, alterando o tamanho de vilos e afetando a absorção e, conseqüentemente, o desempenho das mesmas.

Fatores antinutricionais podem fazer parte de metabolismos especiais ou, ainda, servir como elementos de defesa dos órgãos de reprodução (GONTZEA e SUTZESCU, 1968). Segundo PRICE et al. (1980), o feijão guandu tem uso limitado pela presença de fatores antinutricionais como as lectinas, inibidores de tripsina e tanino. Estas substâncias provocam redução no desempenho de monogástricos, causando diminuição na atividade proteolítica e na utilização de aminoácidos livres (BIEROLAI, 1973) e redução na absorção de gorduras, demonstrado pelo aumento na excreção fecal de lipídios (SKLAN et al., 1973).

Trabalhando com ratos, FREED e BUCKLEY (1979) verificaram redução na eficiência nutricional dos animais. Isto ocorreu, provavelmente, porque algumas lectinas presentes nos alimentos podem causar não somente a proliferação de tecido, mas também aumento na síntese da glicoproteína que compõe o muco produzido nas células caliciformes. Esse aumento na secreção de muco pelas células caliciformes representa um mecanismo de proteção contra danos causados pelas lectinas sobre o epitélio intestinal (Weiser, 1984, citado por PUZSTAI et al., 1991). VOHRA e KRATZE (1966) observaram espessamento do papo, quando frangos de corte receberam $50 \mathrm{~g}$ de ácido tânico na dieta. Por outro lado, MITJAVILA et al. (1977) adicionaram $30 \mathrm{~g}$ de ácido tânico na dieta de ratos e constataram hipersecreção de muco e necrose na mucosa gástrica e duodenal. Os autores sugeriram que a hipersecreção de muco poderia ter efeito protetor para a borda em escova dos enterócitos, ou por formar um complexo muco-tanino.

ORTIZ et al. (1994), testando a inclusão de 0,8 e $16 \mathrm{~g}$ de tanino extraído de feijão (Vicia faba L.) na dieta de frangos de corte, observaram redução do consumo e aumento da conversão alimentar, com o consumo de tanino, além das mortalidades de $33 \mathrm{e}$ $50 \%$ em aves que receberam ração contendo 0,8 e $16 \mathrm{~g}$ de tanino, respectivamente. As observações histológicas mostraram que algumas mudanças ocorreram nas estruturas do íleo e do fígado, como hipertrofia e hiperplasia das células caliciformes, atrofia da superfície da mucosa do íleo e encurtamento de $800 \mu \mathrm{m}$ dos vilos nas aves que receberam a dieta controle, $200 \mu \mathrm{m}$ para as aves que receberam dietas com tanino; além disso, o número de células caliciformes triplicou.

Utilizando farelo de folha de leucena (FFL) proveniente de Malawi, D'MELLO e THOMAS (1978) observaram acentuada diminuição no crescimento e ingestão de alimentos, em pintos com três semanas de idade, utilizando $50 \mathrm{~g}$ de FFL/kg de ração, entretanto, o aumento da conversão alimentar só foi observada em aves consumindo $150 \mathrm{~g} / \mathrm{Kg}$ de ração. PRASAD et al. (1983) verificaram o efeito da inclusão de folhas de Kubabul (L. leucocephala) em dois níveis (3 e $6 \%$ ), nas rações de frango de corte, no período de 10 a 73 dias de idade, e não encontraram diferenças significativas $(\mathrm{P}>0,05)$ no ganho de peso e consumo de alimento em nenhum dos níveis estudados.

Considerando que uma das principais características que torna o frango de corte tão produtivo é a grande capacidade de absorção por área de epitélio intestinal e que existem poucos trabalhos sobre a influência dos fatores antinutricionais sobre este tecido, idealizou-se este trabalho com o objetivo de verificar a influência de fatores antinutricionais, contidos nas leucenas (leucocephala e cunningan) e no feijão guandu (Cajanus cajan) sobre o epitélio intestinal e o desempenho de frangos de corte.

\section{Material e Métodos}

O experimento foi realizado no aviário experimental da Universidade Estadual de Maringá, no período de 21 de outubro a 02 de dezembro de 1997. Foramutilizados 480 pintos machos de 1 dia, distribuídos em um delineamento inteiramente casualizado, com quatro tratamentos, quatro repetições e 30 aves por unidade experimental.

Os tratamentos consistiram de quatro rações: A - ração testemunha à base de milho e soja, B - ração contendo feno de Leucaena leucocephala (6\%), C - contendo feno de Leucaena cunningan $(6 \%) \mathrm{e}$ D - contendo feijão guandu (Cajanus cajan) (20\%). A composição dos ingredientes foi feita de acordo 
Rev. bras. zootec.

Tabela 1 - Composição percentual e calculada das rações experimentais

Table 1 - Percentage and calculated composition of the experimental diets

\begin{tabular}{|c|c|c|c|c|c|c|c|c|}
\hline \multirow[t]{2}{*}{$\begin{array}{l}\text { Ingredientes } \\
\text { Ingredients }\end{array}$} & \multicolumn{4}{|c|}{$\begin{array}{l}\text { Inicial (1-21 dias) } \\
\text { Initial (1-21 days) }\end{array}$} & \multicolumn{4}{|c|}{$\begin{array}{c}\text { Crescimento (21-42 dias) } \\
\text { Growth (21-42 days) }\end{array}$} \\
\hline & A & B & $\mathrm{C}$ & $\mathrm{D}$ & $\mathrm{A}$ & $\mathrm{B}$ & $\mathrm{C}$ & $\mathrm{D}$ \\
\hline $\begin{array}{l}\text { Milho } \\
\text { Corn }\end{array}$ & 59,22 & 54,95 & 55,12 & 41,68 & 66,78 & 62,68 & 62,68 & 47,20 \\
\hline $\begin{array}{l}\text { Farelo de soja } \\
\text { Soybean meal }\end{array}$ & 34,53 & 32,46 & 32,43 & 28,63 & 28,46 & 26,35 & 26,35 & 24,33 \\
\hline $\begin{array}{l}\text { Leucaena } \\
\text { Leucocephala }\end{array}$ & - & 6,00 & - & - & - & 6,00 & - & - \\
\hline Leucaena.cunningan & - & - & 6,00 & - & - & - & 6,00 & - \\
\hline $\begin{array}{l}\text { Cajanus cajan } \\
\text { Fosfato bicálcico }\end{array}$ & $\overline{-}+81$ & - & $\overline{1}, 82$ & $\begin{array}{r}20,00 \\
1,83\end{array}$ & - & - & $\overline{1}-31$ & $\begin{array}{r}20,00 \\
1,31\end{array}$ \\
\hline $\begin{array}{l}\text { Calcário } \\
\text { Limestone }\end{array}$ & 1,14 & 0,85 & 0,85 & 1,13 & 1,12 & 0,83 & 0,83 & 1,10 \\
\hline $\begin{array}{l}\text { Óleo vegetal } \\
\text { Vegetable oil }\end{array}$ & 1,98 & 2,52 & 2,38 & 5,42 & 1,13 & 1,65 & 1,65 & 5,02 \\
\hline $\begin{array}{l}\text { DL-Metionina } \\
\text { DL-Methyonine }\end{array}$ & 0,22 & 0,25 & 0,25 & 0,26 & 0,13 & 0,17 & 0,17 & 0,18 \\
\hline $\begin{array}{l}\text { L-Lisina-HCL } \\
\text { L-lysine - HCL }\end{array}$ & 0,09 & 0,14 & 0,14 & 0,04 & 0,06 & 0,11 & 0,11 & - \\
\hline $\begin{array}{l}\text { Supl.Vit-Mineral } \\
\text { Vit. and min. supplement }\end{array}$ & 0,60 & 0,60 & 0,60 & 0,60 & 0,50 & 0,50 & 0,50 & 0,50 \\
\hline $\begin{array}{l}\text { Antioxidante } \\
\text { Antioxidant }\end{array}$ & 0,10 & 0,10 & 0,10 & 0,10 & 0,10 & 0,10 & 0,10 & 0,10 \\
\hline $\begin{array}{l}\text { Sal } \\
\text { Salt }\end{array}$ & 0,40 & 0,40 & 0,40 & 0,40 & 0,40 & 0,40 & 0,40 & 0,35 \\
\hline $\begin{array}{l}\text { Valor calculado } \\
\text { Calculated value } \\
\end{array}$ & & & & & & & & \\
\hline $\begin{array}{l}\text { Proteína bruta }(\%) \\
\text { Crude protein }\end{array}$ & 21,00 & 21,00 & 21,00 & 21,00 & 18,80 & 18,80 & 18,80 & 18,80 \\
\hline $\begin{array}{l}\text { Energia metabolizável }(\mathrm{kcal} / \mathrm{kg}) \\
\text { Metabolizable energy }\end{array}$ & 3000 & 3000 & 3000 & 3000 & 3050 & 3050 & 3050 & 3050 \\
\hline $\begin{array}{l}\text { Fibra bruta }(\%) \\
\text { Crude fiber }\end{array}$ & 3,30 & 4,20 & 4,20 & 4,30 & 3,00 & 3,90 & 3,90 & 4,00 \\
\hline $\begin{array}{l}\text { Metionina }(\%) \\
\text { Methyonine }\end{array}$ & 0,54 & 0,56 & 0,56 & 0,56 & 0,45 & 0,45 & 0,45 & 0,46 \\
\hline $\begin{array}{l}\text { Lisina }(\%) \\
\text { Lysine }\end{array}$ & 1,19 & 1,19 & 1,19 & 1,20 & 1,02 & 1,02 & 1,02 & 1,02 \\
\hline $\begin{array}{l}\text { Metionina + Cistina }(\%) \\
\text { Methyonine }+ \text { Cystine }\end{array}$ & 0,88 & 0,88 & 0,88 & 0,88 & 0,75 & 0,75 & 0,75 & 0,75 \\
\hline $\begin{array}{l}\text { Cálcio }(\%) \\
\text { Calcium }\end{array}$ & 0,99 & 0,98 & 0,99 & 0,98 & 0,84 & 0,84 & 0,84 & 0,84 \\
\hline $\begin{array}{l}\text { Fósforo disponível (\%) } \\
\text { Available phosphorus }\end{array}$ & 0,45 & 0,44 & 0,44 & 0,45 & 0,35 & 0,35 & 0,35 & 0,35 \\
\hline $\begin{array}{l}\text { Sódio }(\%) \\
\text { Sodium }\end{array}$ & 0,20 & 0,20 & 0,20 & 0,19 & 0,20 & 0,20 & 0,20 & 0,17 \\
\hline
\end{tabular}

1 Suplemento vitamínico e mineral. Composição por $\mathrm{kg}$ de produto (Mineral and vitaminic suplement. Composition per $\mathrm{kg}$ of product): Inicial (Initial). Vit. A - 2.000.000 UI; Vit. D - 320.000 Ul; Vit. E - 4000 mg; Vit. K - 500 mg; Vit. B -240 mg; Vit. B - 800 mg; Vit. B ${ }_{6}$ - 400 mg; Ác. fólico (Folic acid) - 100 mg; Ác. nicotínico (Nicotinic ac.) - 5000 mg; Biotina (Biotine) - 16 mg; Ác. pantotênico (Pantotenic ac.) - 2100 mg; Colina (Choline) - 60.000 mg; Vit. B 12 - 2000 mg; Fe - 10.000 mg; Cu - 1600 mg; Mn - 12.000 mg; Co - 80 mg; Zn - 10.000 mg; - 120 mg; Se - 40 mg; Antioxidante (Antioxidant) - 20.000 mg; Metionina (Methionine) - 217.800 mg; Coccidiostático (Coccidiostatic) - 20.000 mg; Veículo q.s.p. - 1000 g. Crescimento (Growth): Vit. A - 2.000.000 Ul; Vit. D-333.340 Ul; Vit. E-3.340 mg; Vit. K - 500 mg; Vit. B -250 mg; Vit. B - 84 mg; Vit. B - 417 mg; Ácido. fólico (Folic ac.) - 100 mg; Ác. nicotínico (Ac. nicotinic) - 3000 mg; Biotina (Biotin) - 13,5 mg; Ác. pantotênico (Pantotenic ac.) - 2170 mg; Colina (Choline) - 50.000 mg; Vit. B 12084 mg; Fe - 9170 mg; Cu - 1340 mg; Mn - 10.940 mg; Co - 83 mg; Zn - 9170 mg; I 134 mg; Se - 37 mg; Antioxidante (Antioxidant) - 16.670 mg; Metionina (Methionine) - 255.840 mg; Coccidiostático (Coccidiostatic) -10.000 mg; Veículo q.s.p. - 1000 g. 
com ROSTAGNO et al. (1983) e as rações experimentais (Tabela 1) foram formuladas de acordo com as exigências dos animais, sendo uma ração para cada fase: inicial (1 - 21 dias) e de crescimento (21 42 dias). Os parâmetros estudados foram ganho de peso, consumo de ração, conversão alimentar, altura de vilos intestinais, profundidade de cripta, relação vilo:cripta e número de células caliciformes.

As aves foram pesadas no início do experimento, aos 21 e 42 dias de idade. Aos 21 e 42 dias de idade, foram coletados segmentos do duodeno, jejuno e íleo de quatro animais por tratamento, sendo uma ave de cada repetição, de forma aleatória.

Após abate por deslocamento cervical, foi coletado um segmento de um centímetro das referidas regiões intestinais e, a seguir, foram abertas em suas bordas mesentéricas, lavadas, estendidas pela túnica serosa e fixadas, abertas, em solução de Bouin. Esta operação não ultrapassou cinco minutos.

Depois de 3 a 4 horas na solução de Bouin, as amostras foram reduzidas a fragmentos de $0,5 \mathrm{~cm}$, a fim de eliminar as bordas dilaceradas. Permaneceram por mais vinte e quatro horas na solução fixadora e, após, foram lavadas e desidratadas com álcool etílico. Após a desidratação, foram diafanizadas em xilol e incluídas em parafina, de modo a obter cortes longitudinais e transversais da mucosa intestinal.

Em cada lâmina foram colocados quatro cortes semi-seriados com cinco micrômetros de espessura, sendo que entre um corte e o subseqüente foram desprezados doze cortes. Foram preparadas três lâminas por segmento, de cada animal. Os cortes destinados à morfometria foram corados com a técnica da hematoxilina-eosina de Harris e os destinados à contagem de células caliciformes, pela técnica do Ácido Periódico de Schiff-PAS.

Com as lâminas prontas, foram efetuadas trinta medidas de vilosidade $(\mathrm{mm})$ e trinta de profundidade de cripta (mm). As medidas de altura das vilosidades foram tomadas a partir da região basal, que coincide com a porção superior das criptas até o ápice, e as criptas, da base até a região de transição cripta:vilo.

Igual quantidade de lâminas por segmento foi preparada para a contagem de células caliciformes, sendo que foram utilizados materiais de apenas dois animais por tratamento. Foram realizadas 15 contagens por segmento de intestino, sendo uma contagem por vilo.

A análise morfométrica dos segmentos do intestino delgado foi realizada, no Campus da Universidade Estadual Paulista de Jaboticabal, por intermédio um sistema analisador de imagem com aumento de 230 vezes. A contagem de células caliciformes foi feita utilizando-se microscopia óptica e contador digital.

O modelo estatístico utilizado para análise das características estudadas foi:

$$
\mathrm{Y}_{\mathrm{ij}}=\mu+\mathrm{T}_{\mathrm{i}}+\mathrm{I}_{\mathrm{j}}+\mathrm{e}_{\mathrm{ij}}
$$

em que $\mathrm{Y}_{\mathrm{ij}}$ é valor observado do animal $j$ que recebeu a dieta $i ; \mu$, constante geral; T, efeito da dieta $i$, sendo $i=1,2,3$ e $4 ; \mathrm{I}_{\mathrm{j}}$, efeito da idade $j$, sendo $j=21$ e 42; e $e_{i j}$, erro aleatório associado a cada observação.

\section{Resultados e Discussão}

No período inicial, de 1 a 21 dias de idade, houve redução significativa $(\mathrm{P}<0,05)$ do ganho de peso e aumento da conversão alimentar das aves que receberam ração contendo L. leucocephala (L.L) e $L$. cunningan (L.C), em relação às aves que receberam ração testemunha. Entretanto, o consumo de ração não foi influenciado pelos alimentos utilizados (Tabela 2). Estes resultados diferiram parcialmente daqueles obtidos por PRASAD et al. (1983) e D’MELLO e THOMAS (1978), porém estão de acordo com Springhal e Ross (1961), citados por D'MELO e ACAMOVIC (1982), que observaram aumento da conversão alimentar com a utilização de L.L em rações para frangos de corte. Por outro lado, sabe-se que a leucena, após ser ingerida, é degradada a3-dihidroxipiridil, o qual apresenta efeito goitrogênico, reduzindo o consumo de ração. No entanto, o nível de inclusão de leucena, no presente experimento, foi insuficiente para promover tal resposta. Esses dados estão de acordo com HUSSAIN et al. (1991), que observaram redução somente no consumo de ração, quando o nível de inclusão de leucena atingiu 20\% em rações de frangos de corte. Resultados discrepantes são freqüentes na literatura, quando se utiliza leucena nas rações de animais. D'MELLO e FRASER (1981) atribuíram à essa diferença a grande variação no teor de mimosina, de acordo com o estado de maturação, a origem geográfica e o tratamento pós-colheita dado à leucena.

No período de crescimento (21 a 42 dias de idade), não houve efeito significativo $(\mathrm{P}>0,05)$ dos tratamentos sobre o desempenho das aves. Provavelmente ocorreu adaptação ou melhor tolerância das aves aos fatores antinutricionais das dietas neste período, pois, segundo CHUBB (1982), aves mais velhas são menos sensíveis aos ingredientes da dieta. A adaptação dos animais à leucena da dieta foi 
Rev. bras. zootec.

Tabela 2 - Desempenho de frangos de corte alimentados com rações contendo L. Leucocephala (LL), L. cunningan (LC) e C. cajan (CC)

Table 2 - $\quad$ Performance of broilers chickens fed diets containing L. Leucocephala (LL), L. cunningan (LC) and C. cajan (CC)

\begin{tabular}{|c|c|c|c|c|c|}
\hline \multirow{3}{*}{$\begin{array}{l}\text { Variáveis } \\
\text { Variables }\end{array}$} & \multicolumn{4}{|c|}{ Tratamentos } & \multirow[b]{3}{*}{$\mathrm{CV}(\%)$} \\
\hline & \multicolumn{4}{|c|}{ Treatments } & \\
\hline & $\begin{array}{c}\text { Testemunha } \\
\text { Control }\end{array}$ & $\operatorname{LL}(6 \%)$ & $\mathrm{LC}(6 \%)$ & $\mathrm{CC}(20 \%)$ & \\
\hline \multicolumn{6}{|c|}{$\begin{array}{l}\text { Período inicial (1 a } 21 \text { dias) } \\
\text { Initial period ( } 1-21 \text { days) }\end{array}$} \\
\hline $\begin{array}{l}\text { Ganho de peso }(\mathrm{g}) \\
\text { Weight gain }\end{array}$ & $637^{\mathrm{a}}$ & $548^{\mathrm{b}}$ & $549^{\mathrm{b}}$ & $62^{\mathrm{a}}$ & 2,68 \\
\hline $\begin{array}{l}\text { Consumo de ração }(\mathrm{g}) \\
\text { Feed intake }\end{array}$ & 962 & 944 & 955 & 927 & 4,73 \\
\hline $\begin{array}{l}\text { Conversão alimentar } \\
\text { Feed:gain ratio }\end{array}$ & $1,511^{\mathrm{b}}$ & $1,725^{\mathrm{a}}$ & $1,741^{\mathrm{a}}$ & $1,494^{\mathrm{b}}$ & 5,77 \\
\hline \multicolumn{6}{|c|}{$\begin{array}{l}\text { Período de crescimento ( } 21-42 \text { dias) } \\
\text { Growth period ( } 21-42 \text { days })\end{array}$} \\
\hline $\begin{array}{l}\text { Ganho de peso }(\mathrm{g}) \\
\text { Weight gain }\end{array}$ & $1435^{\mathrm{ab}}$ & $1420^{b}$ & $1405^{b}$ & $1503^{\mathrm{a}}$ & 3,07 \\
\hline $\begin{array}{l}\text { Consumo de ração }(\mathrm{g}) \\
\text { Feed intake }\end{array}$ & 2917 & 3003 & 2939 & 3087 & 3,48 \\
\hline $\begin{array}{l}\text { Conversão alimentar } \\
\text { Feed:gain ratio }\end{array}$ & 2,033 & 2,115 & 2,092 & 2,056 & 2,77 \\
\hline \multicolumn{6}{|l|}{ Período total (1-42 dias) } \\
\hline $\begin{array}{l}\text { Total period (1-42 days) } \\
\text { Ganho de peso }(\mathrm{g}) \\
\text { Weight gain }\end{array}$ & $2072^{\mathrm{a}}$ & $1968^{\mathrm{b}}$ & $1953^{b}$ & $2124^{\mathrm{a}}$ & 2,63 \\
\hline $\begin{array}{l}\text { Consumo de ração }(\mathrm{g}) \\
\text { Feed intake }\end{array}$ & 3880 & 3947 & 3894 & 4015 & 2,32 \\
\hline $\begin{array}{l}\text { Conversão alimentar } \\
\text { Feed:gain ratio }\end{array}$ & $1,873^{b}$ & $2,006^{\mathrm{a}}$ & $1,993^{\mathrm{a}}$ & $1,891^{b}$ & 1,609 \\
\hline
\end{tabular}

Médias, na linha, seguidas por letras diferentes, diferem $(\mathrm{P}<0,05)$ pelo teste Duncan.

Means, within a row, followed by different letters are different $(P<.05)$ by Duncan test.

relatada também por D'MELLO e THOMAS (1978), que utilizaram 5 e $10 \%$ de leucena nas dietas de frangos de corte até 14 dias de idade e observaram que essa adaptação, com base no ganho de peso diário, começa a acontecer já na $2^{\mathrm{a}}$ semana de vida das aves.

No período total ( 1 a 42 dias de idade) houve redução significativa $(\mathrm{P}<0,05)$ do ganho de peso e aumento da conversão alimentar para as aves alimentadas com ração contendo LL e LC. Estes resultados diferem dos obtidos por PRASAD et al. (1983) e HUSSAIN et al. (1991), os quais verificaram que a inclusão de folha de L.L não afetou o desempenho de frangos de corte em níveis de 10 e $15 \%$ na ração.

Os resultados de morfometria do epitélio intestinal, no período de 1 a 21 dias de idade, encontram-se na Tabela 3. Houve aumento significativo $(\mathrm{P}<0,05)$ na altura dos vilos, no jejuno de aves alimentadas com LC em relação àquelas alimentadas com a ração testemunha (Figuras 1A e 1B), não diferindo porém das alimentadas com LL. Apesar de não-significativo, ocorreu aumento do tamanho de vilo também para os animais alimentados com rações contendo LL e $C$. cajan (C.C).

Foi observada grande quantidade de eosinófilos no jejuno de aves alimentadas com L.C (Figuras $2 \mathrm{~A}$ e 2B). Os resultados obtidos neste trabalho diferem daqueles obtidos por MITJAVILA et al. (1977), que, trabalhando com ratos, observaram necrose de mucosa gátrica e duodenal causada por tanino e também dos resultados obtidos por ORTIZ et al. (1994), que observaram atrofia e redução do tamanho de vilos na mucosa duodenal de aves que receberam dietas contendo tanino. Por outro lado, os resultados de altura de vilo, obtidos com o presente experimento, estão de acordo com FREED e BUCKLEY (1979), que, trabalhando com ratos, observaram proliferação de tecido do epitétio intestinal causado pela lectina da dieta, e VHORA e KRATZE (1966), os quais constataram espessamento no papo de aves que receberam dietas contendo ácido tânico. 

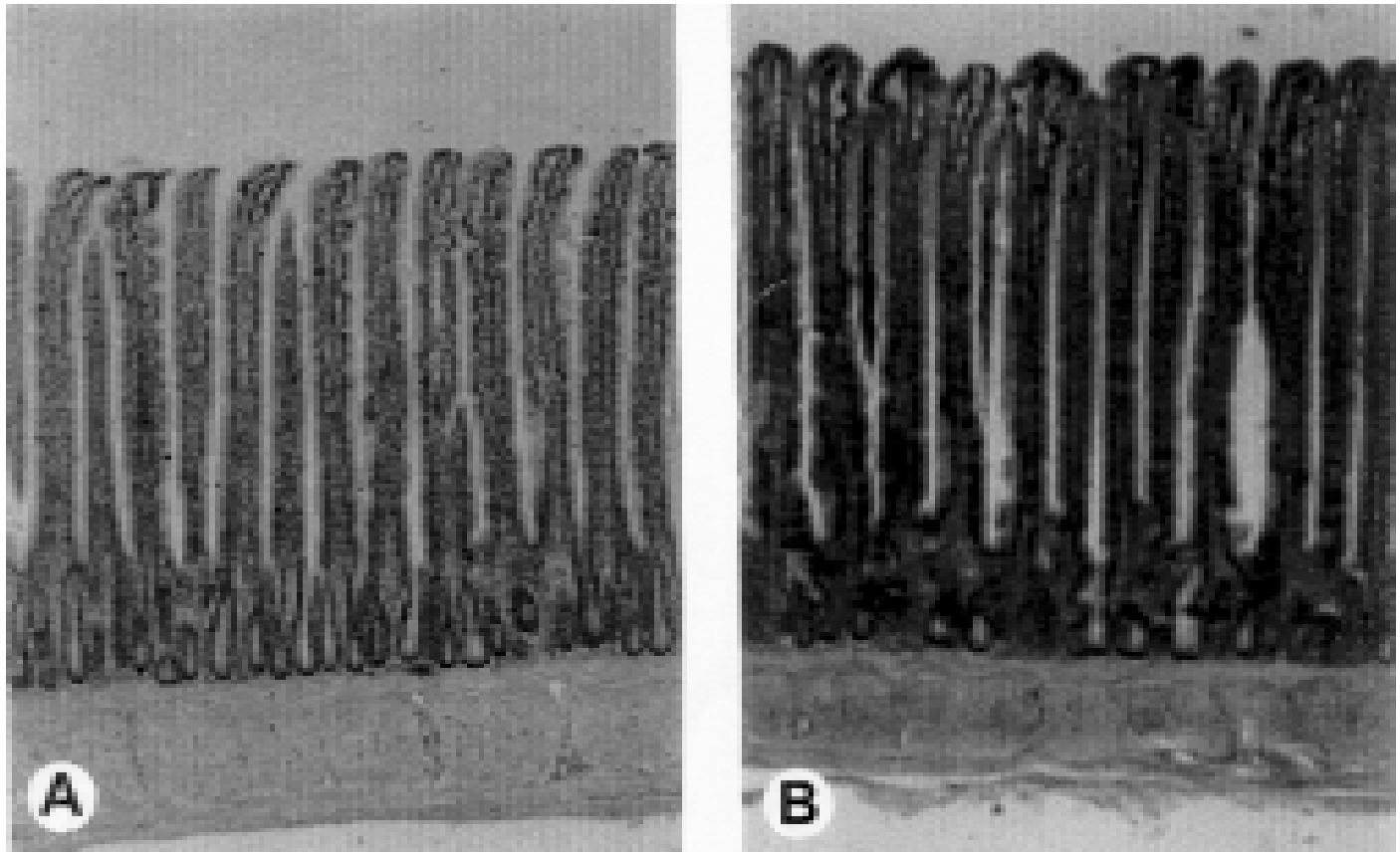

Figura 1 - Fotomicrografias de vilos do jejuno de frangos, aos 21 dias de idade, que receberam ração testemunha e de frangos que receberam ração contendo Leucaena cunningan. Hematoxilina e eosina. $60 \mathrm{X}$.

Figure 1 - Photomicrographs of jejunal villi at 21 day-old broilers, which were fed on basal diet and fed on diets containing Leucaena cunningan. Hematoxylin and eosin stain. $X 60$.

A) Vilos do jejuno de frangos que receberam ração testemunha. Jejunal villi of broilers fed a basal diet.

B) Vilos do jejuno de frangos que receberam ração contendo Leucaena cunningan. Jejunal villi of broilers fed a diet containing Leucaena cunningan.
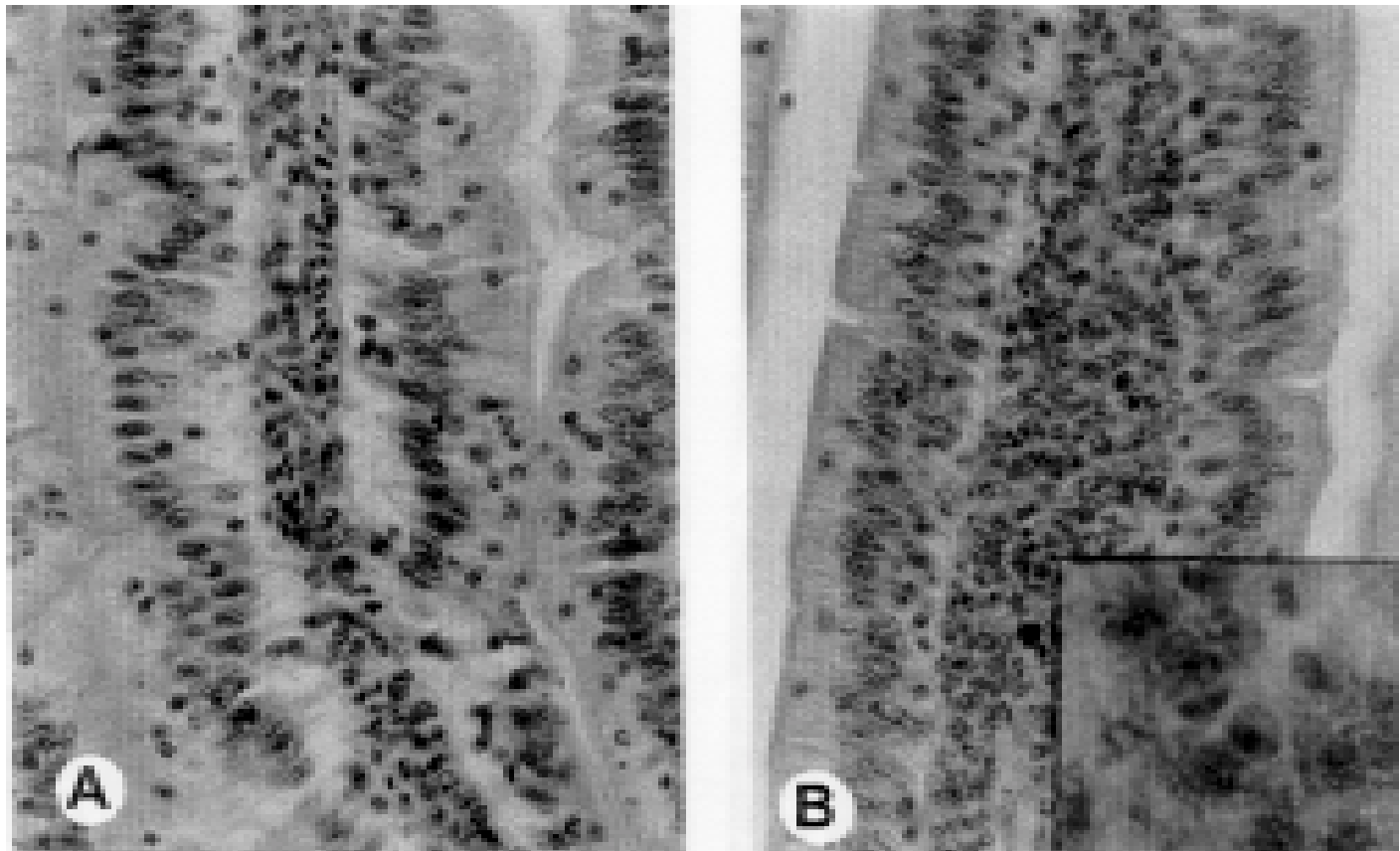

Figura 2 - Fotomicrografias de vilos do jejuno de frangos, aos 21 dias de idade, que receberam ração testemunha e de frangos que receberam ração contendo Leucaena cunningan. P.A.S. 802 X.

Figure 2 - Photomicrographs of jejunal villi at 21 day-old broilers fed a basal diet and broilers fed a diet containing Leucaena cunningan. P.A.S. $X 802$.

A) Aspecto de vilo do jejuno de frangos que receberam ração testemunha.

Aspect of jejunum villus of broilers fed a basal diet.

B) Aspecto de vilo do jejuno de frangos que receberam ração contendo Leucaena cunningan, evidenciando a presença de eosinófilos (E).

Aspect of jejunum villus of broilers fed a diet containing Leucaena cunningan, showing eosinophilus (E). 
Rev. bras. zootec.

Tabela 3 - Morfometria de epitélio intestinal de frangos de corte aos 21 dias de idade, alimentados com rações contendo $L$. Leucocephala (LL) L. cunningan (LC) e C. cajan (CC)

Table 3 - Intestinal epithelium morphometry of broilers chickens at 21 days of age fed on diets containing L. leucocephala (LL), L. cunningan (LC) and Cajanus cajan (CC)

\begin{tabular}{|c|c|c|c|c|c|}
\hline \multirow{3}{*}{$\begin{array}{l}\text { Variáveis } \\
\text { Variables }\end{array}$} & \multicolumn{4}{|c|}{ Tratamentos } & \multirow[b]{3}{*}{$\mathrm{CV}(\%)$} \\
\hline & \multicolumn{4}{|c|}{ Treatments } & \\
\hline & $\begin{array}{c}\text { Testemunha } \\
\text { Control }\end{array}$ & $\operatorname{LL}(6 \%)$ & LC(6\%) & CC (20\%) & \\
\hline \multirow{2}{*}{\multicolumn{6}{|c|}{$\begin{array}{l}\text { Altura de vilo (mm) } \\
\text { Villi height }\end{array}$}} \\
\hline & & & & & \\
\hline $\begin{array}{l}\text { Duodeno } \\
\text { Duodenum }\end{array}$ & 907,9 & 995,1 & 952,0 & 921,7 & 5,98 \\
\hline $\begin{array}{l}\text { Jejuno } \\
\text { Jejunum }\end{array}$ & $756,4^{b}$ & $823,1^{\mathrm{ab}}$ & $882,1^{\mathrm{a}}$ & $767,8^{\mathrm{b}}$ & 6,04 \\
\hline $\begin{array}{l}\text { Íleo } \\
\text { Ileum }\end{array}$ & 563,4 & 632,2 & 630,8 & 561,7 & 8,33 \\
\hline \multicolumn{6}{|c|}{$\begin{array}{l}\text { Profundidade de Cripta (mm) } \\
\text { Crypt depth }\end{array}$} \\
\hline $\begin{array}{l}\text { Duodeno } \\
\text { Duodenum }\end{array}$ & 190,3 & 197,8 & 186,0 & 183,5 & 9,39 \\
\hline $\begin{array}{l}\text { Jejuno } \\
\text { Jejunum }\end{array}$ & 164,3 & 165,8 & 159,0 & 164,0 & 4,72 \\
\hline & 121,9 & 122,7 & 114,3 & 114,3 & 5,60 \\
\hline $\begin{array}{l}\text { Relação vilo } \\
\text { Villi:crypt rat }\end{array}$ & & & & & \\
\hline $\begin{array}{l}\text { Duodeno } \\
\text { Duodenum }\end{array}$ & 4,79 & 5,09 & 5,13 & 5,03 & 8,61 \\
\hline $\begin{array}{l}\text { Jejuno } \\
\text { Jejunum }\end{array}$ & $4,62^{\mathrm{b}}$ & $4,98^{\mathrm{ab}}$ & $5,57^{\mathrm{a}}$ & $4,69^{\mathrm{b}}$ & 10,62 \\
\hline $\begin{array}{l}\text { Íleo } \\
\text { Ileum }\end{array}$ & $4,65^{\mathrm{b}}$ & $5,15^{\mathrm{ab}}$ & $5,54^{\mathrm{a}}$ & $4,92^{\mathrm{ab}}$ & 9,95 \\
\hline
\end{tabular}

Médias, na linha, seguidas por letras diferentes, diferem $(P<0,05)$ pelo teste Duncan.

Means, within a row, followed by different letters are different $(P<.05)$ by Duncan test.

Apesar de causarem danos às vilosidades intestinais, as lectinas, muitas vezes, comportam-se como fatores de crescimento do intestino delgado (PUZSTAI et al., 1991), porém os mecanismos bioquímicos envolvidos ainda não estão esclarecidos.

A presença de eosinófilos observada neste experimento (Figura 2B) indica que ocorreu uma reação alérgica local, pois estas células são responsáveis pela degradação da histamina na anafilaxia, liberada durante a degranulação do mastócito.

Estes resultados estão de acordo com PUZSTAI e GREER (1984), quando observaram que a degranulação do mastócito foi aumentada pela reação de hipersensibilidade imune local causada pelas lectinas em ratos.

Não houve efeito das rações experimentais sobre o tamanho de cripta (Figuras 4A e 4B). Quanto à relação vilo:cripta, verificou-se que houve aumento nesta variável com a utilização de LC tanto no jejuno quanto no íleo, porém, a julgar pelo desempenho das aves nessa fase, o aumento nessa relação não melhorou a capacidade de absorção dos animais.

Aves abatidas aos 42 dias de idade (Tabela 4) não apresentaram diferença significativa $(\mathrm{P}>0,05)$ quanto à altura de vilo, profundidade de cripta ou na relação vilo:cripta, indicando que não houve influência dos fatores antinutricionais dos alimentos sobre estes parâmetros no período de crescimento.

As médias de células caliciformes presentes nas vilosidades das aves, nos diferentes segmentos intestinais, encontram-se na Tabela 5. Nas aves abatidas aos 21 dias de idade, observou-se aumento significativo $(\mathrm{P}<0,05)$ no número de células caliciformes no duodeno (Figuras 3A e 3B) e no jejuno (Figuras 4A e 4B) dos animais que receberam ração contendo LL, LC e CC. Por outro lado, apenas LL e LC, causaram aumento significativo $(\mathrm{P}<0,05)$ do número de células caliciformes no íleo. Estes resultados estão de acordo com ORTIS et al. (1994), que observaram hiperplasia e hipertrofia de células 

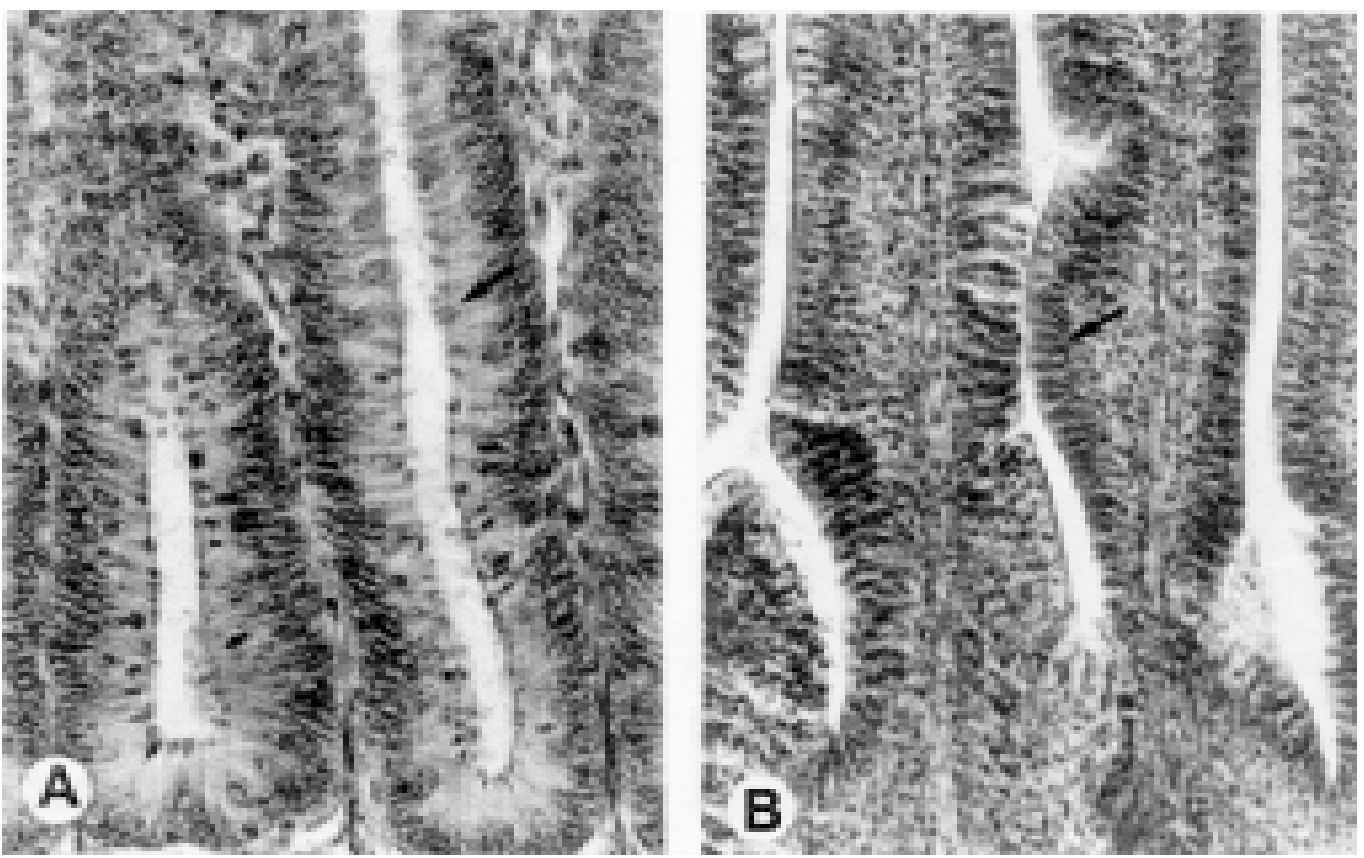

Figura 3 - Fotomicrografias de vilos do jejuno de frangos, aos 21 dias de idade, que receberam ração testemunha e de frangos que receberam ração contendo Leucaena cunningan. P.A.S. 802 X.

Figure 3 - Photomicrographs of jejunal villi at 21 day-old broilers fed a basal diet and broilers fed a diet containing Leucaena cunningan. P.A.S. $X 802$.

A) Aspecto de vilo do jejuno de frangos que receberam ração testemunha. As setas indicam células caliciformes. Aspect of jejunum villus of broilers fed a basal diet. Arrows show Goblet cells.

B) Aspecto de vilo do jejuno de frangos que receberam ração contendo Leucaena leucocephala. As setas indicam grande quantidade de células caliciformes.

Aspect of jejunum villus of broilers fed a diet containing Leucaena leucocephala. Arrows show many Goblet cells.
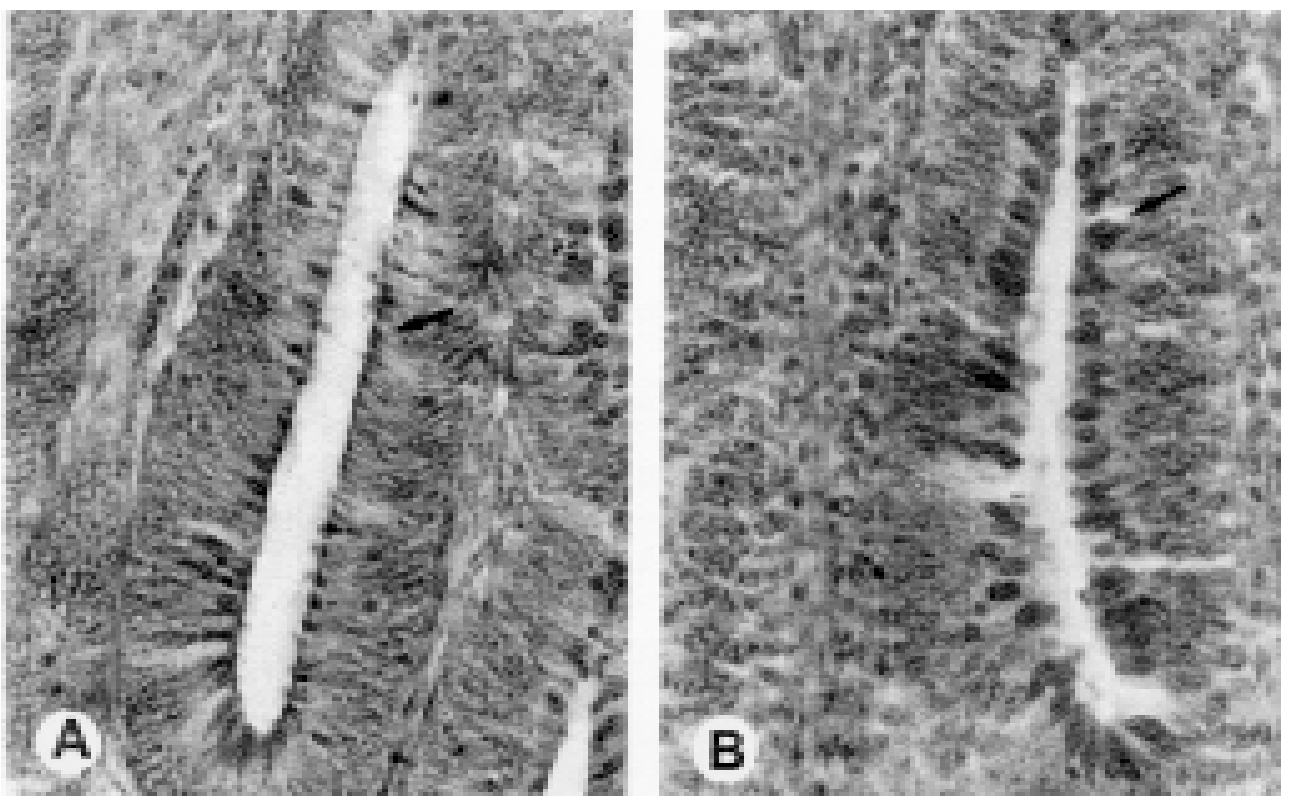

Figura 4 - Fotomicrografias da cripta de Lieberkuhn do jejuno de frangos, aos 21 dias de idade, que receberam ração testemunha e de frangos que receberam ração contendo Leucaena cunningan. P.A.S. 802 X.

Figure 4 - Photomicrographs of Lieberkuhn crypt of jejunum at 21 day-old broilers fed a basal diet and broilers fed a diet containing Leucaena cunningan. P.A.S. X 802.

A) Aspecto da cripta de Lieberkuhn do jejuno de frangos que receberam ração testemunha. As setas indicam células caliciformes.

Aspect of Lieberkuhn crypt of jejunum of broilers fed a basal diet. Arrows show Goblet cells.

B) Aspecto de vilo do jejuno de frangos que receberam ração contendo Leucaena leucocephala. As setas indicam grande quantidade de células caliciformes.

Aspect of Lieberkuhn crypt of jejunum of broilers fed a diet containing Leucaena leucocephala. Arrows show many Goblet cells. 
Rev. bras. zootec.

Tabela 4 - Morfometria de epitélio intestinal de frangos de corte, aos 42 dias de idade, alimentados com rações contendo L. Leucocephala (LL), L. cunningan (LC) e C. cajan (CC)

Table 4 - Intestinal epithelium morphometry of broilers at 42 days of age fed diets containing L. Leucocephala (LL), L. cunningan (LC) and C. cajan (CC)

\begin{tabular}{|c|c|c|c|c|c|}
\hline \multirow{3}{*}{$\begin{array}{l}\text { Variáveis } \\
\text { Variables }\end{array}$} & \multicolumn{4}{|c|}{ Tratamentos } & \multirow[b]{3}{*}{$\mathrm{CV}(\%)$} \\
\hline & \multicolumn{4}{|c|}{ Treatments } & \\
\hline & $\begin{array}{l}\text { Testemunha } \\
\text { Control }\end{array}$ & $\operatorname{LL}(6 \%)$ & $\mathrm{LC}(6 \%)$ & $\mathrm{CC}(20 \%)$ & \\
\hline \multirow{2}{*}{\multicolumn{6}{|c|}{$\begin{array}{l}\text { Altura de vilo (mm) } \\
\text { Villi height }\end{array}$}} \\
\hline & & & & & \\
\hline $\begin{array}{l}\text { Duodeno } \\
\text { Duodenum }\end{array}$ & 1323,5 & 1340,1 & 1321,4 & 1319,0 & 5,22 \\
\hline Jejuno & 1072,9 & 1054,1 & 1035,8 & 1083,8 & 6,40 \\
\hline $\begin{array}{l}\text { Jejunum } \\
\text { Îleo } \\
\text { Ileum }\end{array}$ & 717,3 & 758,5 & 785,5 & 777,7 & 14,43 \\
\hline \multicolumn{6}{|c|}{$\begin{array}{l}\text { Profundidade de cripta }(\mathrm{mm}) \\
\text { Crypt depth }\end{array}$} \\
\hline $\begin{array}{l}\text { Duodeno } \\
\text { Duodenum }\end{array}$ & 287,4 & 281,1 & 285,1 & 294,6 & 7,69 \\
\hline $\begin{array}{l}\text { Jejuno } \\
\text { Jejunum }\end{array}$ & 229,8 & 218,7 & 216,5 & 239,5 & 8,52 \\
\hline $\begin{array}{l}\text { Íleo } \\
\text { Ileum }\end{array}$ & 140,5 & 138,0 & 135,0 & 135,7 & 7,97 \\
\hline \multicolumn{6}{|c|}{$\begin{array}{l}\text { Relação vilo:cripta }(\mathrm{mm}) \\
\text { Villi:crypt ratio }\end{array}$} \\
\hline $\begin{array}{l}\text { Duodeno } \\
\text { Duodenum }\end{array}$ & 4,61 & 4,78 & 4,71 & 4,51 & 11,81 \\
\hline Jejuno & 4,69 & 4,83 & 4,81 & 4,54 & 6,78 \\
\hline $\begin{array}{l}\text { Jejunum } \\
\text { Îleo } \\
\text { Ileum }\end{array}$ & 5,11 & 5,48 & 5,85 & 5,72 & 12,34 \\
\hline
\end{tabular}

Tabela 5 - Número de células caliciformes presentes no epitélio intestinal de frangos de corte alimentados com rações contendo $L$. Leucocephala (LL), L. cunningan (LC) e C. cajan (CC)

Table 5 - Goblets cells numbers present in the intestinal epithelium of broilers fed diets containing L. Leucocephala (LL), L. cunningan (LC) and C. cajan (CC)

\begin{tabular}{|c|c|c|c|c|c|}
\hline \multirow{3}{*}{$\begin{array}{l}\text { Variáveis } \\
\text { Variables }\end{array}$} & \multicolumn{4}{|c|}{ Tratamentos } & \multirow[b]{3}{*}{$\mathrm{CV}(\%)$} \\
\hline & \multicolumn{4}{|c|}{ Treatments } & \\
\hline & $\begin{array}{l}\text { Testemunha } \\
\text { Control }\end{array}$ & $\operatorname{LL}(6 \%)$ & $\mathrm{LC}(6 \%)$ & $\mathrm{CC}(20 \%)$ & \\
\hline \multicolumn{6}{|c|}{ Período inicial(1-21 dias) } \\
\hline \multicolumn{6}{|c|}{ Initial period 1-21 days } \\
\hline & $134^{\mathrm{c}}$ & $258^{\mathrm{a}}$ & $278^{a}$ & $226^{\mathrm{b}}$ & 5,06 \\
\hline $\begin{array}{l}\text { Jejuno } \\
\text { Jejunum }\end{array}$ & $160^{c}$ & $294^{\mathrm{a}}$ & $323^{a}$ & $244^{\mathrm{b}}$ & 4,51 \\
\hline $\begin{array}{l}\text { Íleo } \\
\text { Ileum }\end{array}$ & $203^{b}$ & $345^{\mathrm{a}}$ & $366^{\mathrm{a}}$ & $261^{\mathrm{b}}$ & 7,34 \\
\hline \multicolumn{6}{|c|}{$\begin{array}{l}\text { Período de crescimento ( } 21-42 \text { dias) } \\
\text { Growth period } 21-42 \text { days }\end{array}$} \\
\hline $\begin{array}{l}\text { Duodeno } \\
\text { Duodenum }\end{array}$ & $249^{b}$ & $253^{\mathrm{ab}}$ & $255^{\mathrm{ab}}$ & $260^{\mathrm{a}}$ & 2,46 \\
\hline $\begin{array}{l}\text { Jejuno } \\
\text { Jejunum }\end{array}$ & 255 & 253 & 244 & 276 & 4,85 \\
\hline $\begin{array}{l}\text { Íleo } \\
\text { Ileum }\end{array}$ & $258^{\mathrm{b}}$ & $298^{\mathrm{a}}$ & $292^{\mathrm{a}}$ & $299^{\mathrm{a}}$ & 3,44 \\
\hline
\end{tabular}

Médias, na linha, seguidas por letras diferentes, diferem $(P<0,05)$ pelo teste Duncan.

Means, within a row, followed by different letters are different $(P<0.05)$ by Duncan test. 

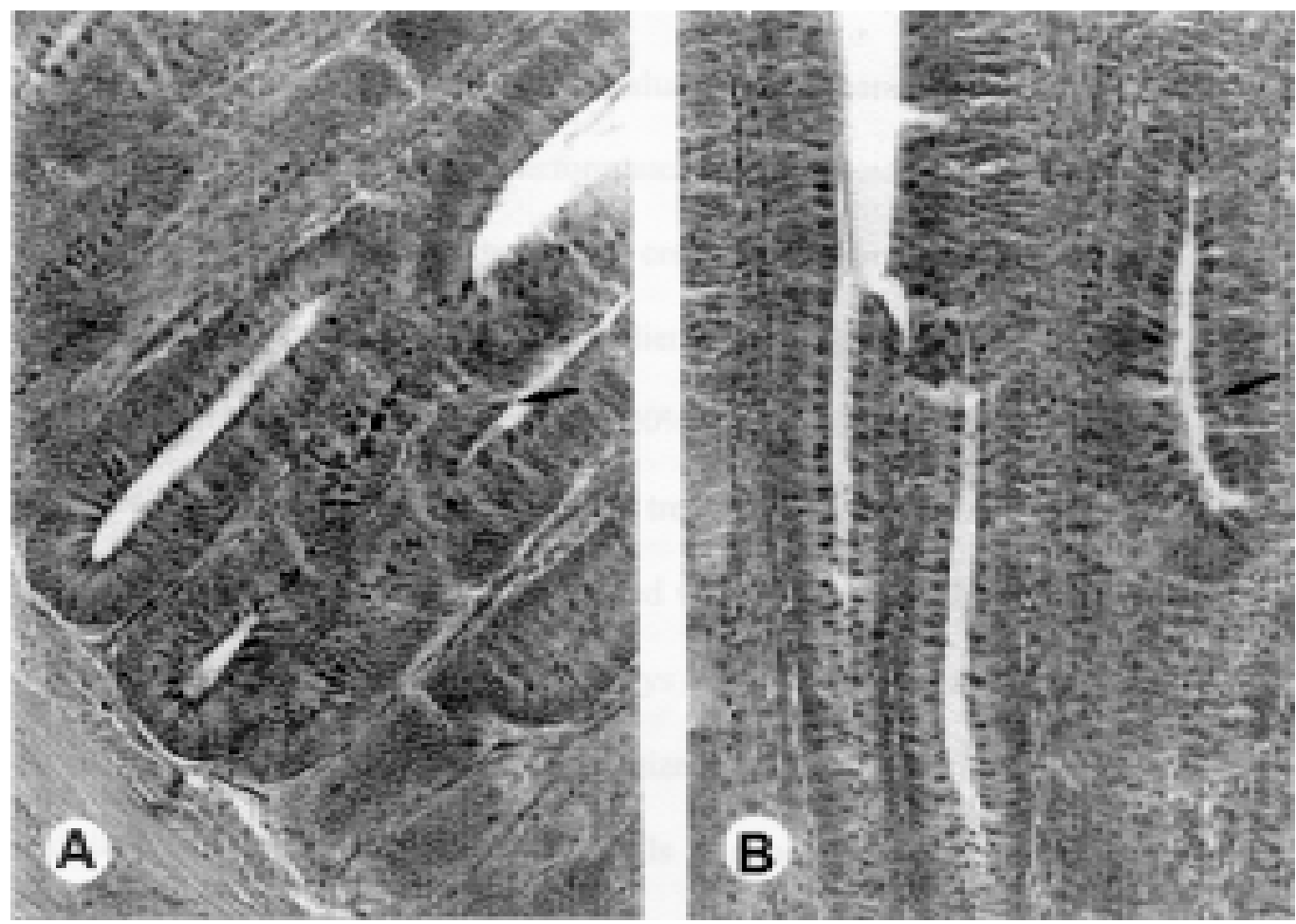

Figura 5 - Fotomicrografias do duodeno de frangos, aos 42 dias de idade, que receberam ração testemunha e de frangos que receberam ração contendo Cajanus cajan. P.A.S. 802 X.

Figure 5 - Photomicrographs of duodenum at 42 day-old broilers fed a basal diet and broilers fed a diet containing Cajanus cajan. P.A.S. $X 802$.

A) Aspecto da cripta de Lieberkuhn do jejuno de frangos que receberam ração testemunha. As setas indicam células caliciformes.

Aspect of Lieberkuhn crypt of jejunum of broilers fed a basal diet. Arrows show Goblet cells.

B) Aspecto de vilo do jejuno de frangos que receberam ração contendo Leucaena leucocephala. As setas indicam grande quantidade de células caliciformes.

Aspect of Lieberkuhn crypt of jejunum of broilers fed a diet containing Leucaena leucocephala. Arrows show many Goblet cels.

caliciformes em frangos de corte alimentados com dietas contendo tanino.

Em aves abatidas aos 42 dias de idade, observou-se aumento no número de células caliciformes, do duodeno, em animais que receberam ração contendo CC, e do íleo (Figuras 5A, 5B), em todos os tratamentos. Os resultados indicam que, mesmo na fase de crescimento, pode ter ocorrido produção excessiva de muco, causada pelos fatores antinutricionais presentes nos alimentos utilizados. Estes resultados estão de acordo com DIBNER et al. (1996), que trabalharam com aves e observaram que mesmo na fase adulta esses animais são sensíveis aos componentes da dieta.

\section{Conclusões}

A utilização de Leucaena cunningan e Leucaena leucocephala em dietas de frangos de corte acarretou redução no ganho de peso e aumento na conversão alimentar na fase inicial e no período total.

Dietas contendo Leucaena cunningan, Leucaena leucocephala e Cajanus cajan causaram aumento no número de células caliciformes, nas fases inicial e de crescimento. A presença de Leucaena cunningan afetou a morfometria do epitélio intestinal, aumentando o tamanho de vilos do jejuno e a relação vilo:cripta no jejuno e no íleo na fase inicial.

As alterações da morfometria do epitélio intestinal, 
causada pelos fatores antinutricionais da Leucaena cunningan e Leucaena leucocephala, influíram no baixo desempenho das aves.

\section{Referências Bibliográficas}

BIELORAI, R., TAMIR, M., BAR, A., HURWITZ, S. 1973. Digestion and absortion of protein along intestinal tract of chick fed raw and heated soybean meal. J. Nut., 103:12011226.

CHUBB, L.G. 1982. Anti-nutritive factors in animal feedstuffs. In: HARESING, W. Studies in agricultural food sciences. Butterworths. p.21-23.

DIBNER, J.J., KITCHELL, M.L., ATWELL, C.A.A. et al. 1996. The effect of dietary ingredients and age on the microscopic structure of the gastrointestinal tract in poultry. J. Applied Poult. Sci., 5(3):70-77.

D'MELLO, J. P. F., ACAMOVIC, T. 1982. Growth performance and mimosine excretion by young chicks fed on Leucaena leucocephala. Anim. Feed Sci. Techn., 7(2):247-255.

D'MELLO, J.P.F., FRASER, K.W. 1981. The composition of leaf meal from Leucaena leucocephala. Tropic. Sci., 23(1):75-78.

D'MELLO, J.P.F., THOMAS, D. 1978. The nutritive value of the leucaena leaf meal from Malawi studies with young chicks. Tropical Agricultural Trinidad, 55:45-50.

FREED, D.L.J., BUCKLEY, C.H. 1979. Mucotractive effect of lectin. 7.ed. Lancet. 58p.

GONTZEA, I., SUTZESCU, P. 1968. Natural antinutritive substances in feedstuffs and forages. 3.ed. New York: S. Karger, NY. 356p.

HUSSAIM, J., SATYANARAYANA, P.V.V., REDDY, V.R. 1991. Utilization of leucaena leaf meal by broilers. British Poult. Sci., 32:131-137.
MITJAVILA, S., LACOMBE, C., ARRERA, G. et al. 1977 Tannic acid oxided on the functional state of rat intestinal epithelium. J. Nut., 107:2113-2121.

ORTIZ, L.T., ALZUETA, C., TREVIÑO, J. et al. 1994. Effects of fava beans tannins on the growth and histological structure of the intestinal tract and liver of chicks and rats. British Poult. Sci., 35:743-754.

PRASAD, C.M., SINGH, R.L., PRASAD, LK. et al. 1983. Effect of feeding kubabul (Leucaena leucocephala) leaf-meal on commercial broilers. Ind. J. Anim. Sci., 53:111-113.

PRICE, M.L., HAGERMAN, A.E., BUTLER, L.G. 1980. Tannin content of cow peas, chickpeas, pigeon peas and mung beans. J. Agric. Food Chem., 28:459-461.

PUSZTAI, A., GREER, F. 1984. Effect of dietary legume proteins on the morphology and secretory responses to the rat small intestine. Protides of the Biological Fluids, 32:347-350.

PUZSTAI, A., BEGBIE, R., GRANT, G. et al. 1991. Indirect effects of food nutrients on protein digestibility and nutritional value of diets. In: CHEEK, P.R. (Ed) In vitro digestion for pigs and poultry. C.A.B. International. Press, Boca Raton, p.29-71.

ROSTAGNO, H.S., SILVA, D.J., COSTA, P.M.A. et al. 1983. Composição de alimentos e exigências nutricionais de aves e suínos (Tabelas Brasileiras). Viçosa, MG: UFV, Imprensa Universitária. p.59.

SKLAN, P., BUDOWSKI, P., ASCARELLI, I. I. et al. 1973. Lipid absorption and secretion in chick. J. Nut., 103:1299.

VHORA, P., KRATZE, F. H. 1966. Influence of various phosfates and other complexing agents on the availability of zinc for turkey. J. Nut., 79:106.

Recebido em: $14 / 12 / 99$

Aceito em: 18/05/00 